\title{
Interaction between COMT rs5993883 and second generation antipsychotics is linked to decreases in verbal cognition and cognitive control in bipolar disorder
} (1) CrossMark

\author{
Stephanie A. Flowers' ${ }^{1}$ Kelly A. Ryan², Zongshan Lai ${ }^{2,3}$, Melvin G. Mclnnis ${ }^{2}$ and Vicki L. Ellingrod ${ }^{1,2^{*}}$
}

\begin{abstract}
Background: Second generation antipsychotics (SGAs) are increasingly utilized in Bipolar Disorder (BD) but are potentially associated with cognitive side effects. Also linked to cognitive deficits associated with SGA-treatment are catechol-O-methyltransferase (COMT) gene variants. In this study, we examine the relationship between cognition in SGA use and COMT rs5993883 in cohort sample of subjects with BD.

Methods: Interactions between SGA-treatment and COMT rs5993883 genotype on cognition was tested using a battery of neuropsychological tests performed in cross-sectional study of 246 bipolar subjects.

Results: The mean age of our sample was 40.15 years and was comprised of $70 \%$ female subjects. Significant demographic differences included gender, hospitalizations, benzodiazepine/antidepressant use and BD-type diagnosis. Linear regressions showed that the COMT rs5993883 GG genotype predicted lower verbal learning $(p=0.0006)$ and memory $(p=0.0026)$ scores, and lower scores on a cognitive control task $(p=0.004)$ in SGA-treated subjects. Interestingly, COMT GT- or TT-variants showed no intergroup cognitive differences. Further analysis revealed an interaction between SGA-COMT GG-genotype for verbal learning $(p=0.028)$, verbal memory $(p=0.026)$ and cognitive control ( $p=0.0005)$.

Conclusions: This investigation contributes to previous work demonstrating links between cognition, SGA-treatment and COMT rs5993883 in BD subjects. Our analysis shows significant associations between cognitive domains such as verbal-cognition and cognitive control in SGA-treated subjects carrying the COMT rs5993883 GG-genotype. Prospective studies are needed to evaluate the clinical significance of these findings.
\end{abstract}

Keywords: Cognition, Second generation antipsychotic, COMT, Bipolar disorder

\section{Background}

Second generation Antipsychotics (SGAs) are distinguished from first generation antipsychotics by the ability to control psychosis at doses associated with considerably fewer extrapyramidal symptoms and a relatively greater 5HT2A/D2 binding affinity ratio [1]. This class of medication is increasingly utilized in the long-term treatment of Bipolar Disorder (BD) as an alternative monotherapy or

\footnotetext{
* Correspondence: vellingr@med.umich.edu

'Clinical Pharmacy Department, College of Pharmacy, University of Michigan, 428 Church St, Ann Arbor, Ml 48109-106, USA

${ }^{2}$ Department of Psychiatry, School of Medicine, University of Michigan, 4250 Plymouth Rd, Ann Arbor, Ml 48109, USA

Full list of author information is available at the end of the article
}

more often as an adjunct treatment with lithium or anticonvulsant agents. Significant underlying cognitive deficits in BD patients have not only been observed in manic or depressive episodes but also when euthymic, compared to healthy controls [2-4]. Various medical or lifestyle factors may influence cognitive functioning in this patient population but the contribution of pharmacologic treatment to deficits in cognition remains unclear. In schizophrenia, evidence suggests that cognitive improvements after the initiation of treatment have more to do with practice effects such as exposure, familiarity and/or procedural learning than the implementation of second generation antipsychotics [5]. However, there remains an abundance 
of recent findings to suggest there are cognitive effects associated with SGA-treatment. Unlike the cognitive benefits observed in some studies for SGA therapy in the schizophrenia population [6-8], evidence indicates that SGAs may have a further detrimental effect on cognition in BD independent of other clinical factors $[9,10]$. These data highlight the need to investigate this issue in a large, well-characterized sample of patients with BD.

Previous studies have shown that the regulation of dopamine and dopamine receptors play a role in BD pathophysiology and also in cognitive processes [11, 12]. Contributing to dopamine signaling pathways are both environmental and genetic factors. Catechol-O-methyltransferase (COMT) is a major enzyme involved in dopamine metabolism in the prefrontal cortex and has been associated with numerous psychiatric phenotypes [13-15]. The COMT Val108/158Met polymorphism (rs4680) and Val allele load is associated with decreased cognitive performance, such as in executive functioning and working memory in both schizophrenia and BD subjects [16-19]. Although not thoroughly characterized, other COMT variants impacting cognition in $\mathrm{BD}$ subjects have been described $[16,20]$. The objective of this study was to compare neuropsychological performance of SGA vs non-SGA treated bipolar patients with different allelic representation of the COMT variants. As previous associations link cognition deficits to treatment with SGAs and COMT variant alleles in the BD population, we hypothesize this COMT variant would result in decreased cognitive scores in BD patients who are treated with SGAs.

\section{Methods}

\section{Subjects}

The Prechter Longitudinal Study of Bipolar Disorder is an ongoing observational study of bipolar disorder at the University of Michigan (HUM00000606) with the main goal of gathering phenotypic data and biological material [21]. The present study included 246 individuals from this cohort with a DSM-IV diagnosis of BD (BD Type I $(n=178)$, BD Type II $(n=39)$, BD not otherwise specified (NOS, $n=21$ ), Schizoaffective disorder-bipolar type $(n=8))$. All subjects underwent an evaluation using the Diagnostic Interview for Genetic Studies (DIGS; [22]), neuropsychological testing, clinician questionnaires to assess symptoms of depression and mania (Hamilton Depression Rating-17 item (HDRS; [23]) and Young Mania Rating Scale (YMRS; [24]). Diagnoses were confirmed using a best estimate process by at least three $\mathrm{MD} / \mathrm{PhD}$ clinicians. Medication groups were defined as the use of an SGA at the time of cognitive testing. Second generation antipsychotics, concomitant benzodiazepines and antidepressants used by our cohort are listed in Additional file 1: Table S1. For this cross-sectional analysis, the medication treatment class, neuropsychological performance, age, gender, years of education, time since BD diagnosis, treatment with benzodiazepines or antidepressants and number previous hospitalizations were noted in these subjects.

\section{Neuropsychological tests}

Neuropsychological tests were administered by trained research associates under the supervision of licensed clinicians. The test battery was intended to emphasize known areas affected by BD illness and reported in our prior work $[4,25]$. Five specific tests were selected from the original test battery to capture areas that seem to be most sensitive to COMT variants. The California Verbal Learning Test-II (CVLT-II, [26]) was used a measure of verbal learning and memory. In this task, five consecutive trials of 16 words are presented and overall learning across the 5 trials was recorded. There was a short-term delayed free recall trial after a distractor list and a longterm delayed free recall trial after $20 \mathrm{~min}$. The ReyOsterrieth Complex Figure Test (Rey, [27, 28]) was used as a measure of visual learning and memory and required subjects to draw from memory a complex figure that they previously copied and then to recall from memory the figure again after $20 \mathrm{~min}$. To assess executive functioning, the Wisconsin Card Sorting Test (WCST, [29]), a measure of novel problem solving task, and the Trail Making Test (Parts A and B: TMT, [30]), a measure of set-shifting and sequencing, were administered. For the WCST, subjects had to sort cards according to a sorting strategy that they learned based on receiving feedback about prior sorts. Number and type of errors were recorded as well as how many categories sorted. For the TMT Part A, subjects had to manually connect dots in order of numbers that were presented in a spatial array. For the TMT Part B, subjects had to alternate connecting numbers and letters. Total seconds to complete each task was recorded. To assess cognitive control (the ability to engage and disengage in response behaviors), often seen as an element of attention, we used the Parametric Go/No-Go task (PGNG, [31]), a computerized continuous performance test that consists of three separate levels, but only the first level was used for this study. The first level measures attention and response time, resulting in two measures of cognitive control. Subjects respond to a serial stream of letters, pressing a keyboard as quickly as possible whenever they see specific letter.

\section{Genotyping}

Genotyping was done using the HumanCoreExome-12v1 DNA Analysis BeadChip Kit (Illumina, INC., San Diego, CA). Samples were genotyped for greater than 240,000 tagSNP markers and more than 240,000 exome markers 
by the University of Michigan DNA Sequencing Core. DNAs were quantified using the Quant-i ${ }^{\mathrm{TM}}$ PicoGreen ${ }^{\circ}$ dsDNA Kit (Invitrogen Corporation, Carlsbad, CA) and samples were assayed according the Illumina Infinium ${ }^{\circ} \mathrm{HD}$ Ultra Protocol. BeadChip image data was recorded using an Illumina iScan Mircroarray Scanner with the Infinium NXT scan setting. Sample image data were analyzed and genotypes determined using the Illumina GenomeStudio (v2011.1) DNA Analysis Software package with Genotyping Modulue (v1.9.4) using the HumanCoreExome-12v10_B Manifest and HumanCoreExome-12v1-0_B Cluster file from Illumina. To limit false positives, we conducted a priori analysis with COMT due to previous associations with COMT variants and cognition. Two SNPS available for analysis were COMT rs5993882 and rs165599. Initial data for rs165599 did not show any association with SGA use and cognition and therefore, we focused our analysis on rs5993882.

\section{Statistical analyses}

Hardy-Weinberg equilibrium was tested by a Chi Square analysis. Demographic differences between treatment groups were examined with a standard $t$-test or one-way ANOVA for continuous variables and a chi-square for nominal variables. We performed linear regressions for the multiple variable analyses. For the first linear regression, the cognitive test scores in treatment groups (SGAtreated vs. non-SGA treated) were compared for the three COMT rs5993882 genotypes (GG, GT, TT). We adjusted the model for known predictors that may confound cognitive performance, such as age, years of education, gender, diagnosis, benzodiazepine or antidepressant concomitant use, and prior hospitalizations. For tests that were statistically significant, we additionally ran a follow-up analysis using chlorpromazine (CPZ) equivalents as a continuous variable. The second linear regression also was adjusted for these covariates but included new predictors such as COMT genotype and an SGA- COMT interaction. In the second regression model, the GG COMT genotype was used as the comparator for the combined GT and TT genotypes.

Due to the number of cognition test scores, we have adjusted the significance value for regression model 1 using a Bonferroni correction for multiple testing ( $p \leq 0.0043)$. For analysis using CPZ-equivalent doses and regression model two, we considered a p value of $\leq 0.05$ to be significant. All analyses were conducted in SAS 9.3 (Cary, NC, USA).

\section{Results}

\section{SNP and haplotype association}

Fifty eight patients were homozygous for the COMT rs5993882 GG genotype, 120 patients were heterozygous (GT) and 52 patients were homozygous for the TT genotype. No significant deviations from Hardy-Weinberg equilibrium were observed for the COMT rs5993882 in the tested population $(p>0.5)$.

\section{Study population characteristics}

Table 1 represents the demographic parameters of our study population. As cognition can be affected by a number of factors such as age, years of education, gender, diagnosis, severity of $\mathrm{BD}$ and concomitant medications, these demographics were used as confounders in our regression models to account for differences between the different genotypes. Our analysis showed significant intergroup differences in gender, concomitant benzodiazepine or antidepressant use, and type of BD diagnosis (see Table 1) with non-SGA treatment group containing more females, less concomitant benzodiazepine and antidepressant use and increased BD-II, BD NOS diagnosed subjects. Mood symptom scores (HAMD, YMRS), recorded at the same time as cognitive testing, showed no statistical differences between treatment populations. As SGAs can be associated with greater severity of BD illness, intergroup variances between time since $\mathrm{BD}$ diagnosis and number of previous hospitalizations were also noted. The SGAtreatment group showed a statistically higher number of hospitalizations and this was adjusted for in our regression analysis.

\section{Analysis of COMT genotypes and cognition in SGA- treated BD patients}

We initially examined the association of cognitive deficits in SGA-treated subjects stratified by their COMT rs5993883 genotypes (linear regression 1; Table 2). We adjusted this model for age, education, gender, type of BD diagnosis, number of hospitalizations, as well as treatment with benzodiazepines and antidepressants. Our model showed that the GG allele genotype was associated with statistically significant lower scores in specific cognitive domains, such as verbal memory and cognitive control, in subjects treated with an SGA compared to those treated with SGA and with a GT and TT allele. Second generation antipsychotic-treated subjects homozygous for the GG genotype showed a significantly worse CVLT-II verbal learning score when compared to non-SGA treated patients who also carry the GG genotype $\left(p=0.0006 ; \beta=-10.88 ; r^{2}=0.51\right)$. Although there were no differences between treatment groups for shortterm verbal memory (CVLT-II), long-term delayed verbal memory was significantly lower in SGA-treated subjects with the GG genotype $\left(p=0.0026 \beta=-3.43 ; r^{2}=.28\right)$ compared to non-SGA treated subjects with the same genotype. The same analysis using CPZ-equivalents found similar findings noting worse CVLT-II verbal learning $(p=$ $\left.0.009 ; \beta=-0.02 ; r^{2}=0.45\right)$ and verbal memory $(p=0.016$; $\left.\beta=-0.009 ; r^{2}=0.23\right)$ in subjects with GG genotypes and higher CPZ-equivalent doses. Subjects treated with SGAs 
Table 1 Demographic characteristics

\begin{tabular}{|c|c|c|c|}
\hline & NO-SGA $A^{a}$ & $S G A^{a}$ & $p$ value \\
\hline & $N(\%)$ or & $N(\%)$ or & \\
\hline & Mean (SD) & Mean (SD) & \\
\hline Gender & & & \\
\hline Female & $119(69.2)$ & $41(55.4)$ & 0.037 \\
\hline Male & $53(30.8)$ & $33(44.6)$ & \\
\hline Years of education in years (SD) & $15.4(2.9)$ & $15.2(3.2)$ & 0.63 \\
\hline Age in years (SD) & $40.3(12.9)$ & $40(11.3)$ & 0.83 \\
\hline Time since diagnosis in years (SD) & $14.3(11.7)$ & $13.9(10.7)$ & 0.75 \\
\hline Previous hospitalizations & $113(65.7)$ & $58(78.4)$ & 0.047 \\
\hline Medications & & & \\
\hline Benzodiazepines & $28(16.3)$ & $26(35.1)$ & 0.001 \\
\hline Antidepressants & $48(27.9)$ & $37(50.0)$ & 0.0008 \\
\hline Chlorpromazine equivalents & NA & $210(787)$ & \\
\hline Mood symptoms & & & \\
\hline HAMD $^{\mathrm{b}}$ & $8.9(6.6)$ & $8.2(6)$ & 0.43 \\
\hline YMRS $^{c}$ & $3.1(4.1)$ & $3.2(3.8)$ & 0.85 \\
\hline Diagnosis & & & \\
\hline Bipolar I & $115(66.9)$ & $63(85.1)$ & 0.014 \\
\hline Bipolar II with recurrent depression & $34(19.7)$ & $5(6.8)$ & \\
\hline Bipolar NOS ${ }^{d}$ & $18(10.5)$ & $3(4.0)$ & \\
\hline Schizoaffective, Bipolar & $5(2.9)$ & $3(4.0)$ & \\
\hline COMT rs5993883 & & & \\
\hline GG & $44(25.6)$ & $14(18.9)$ & 0.5 \\
\hline GT & $88(51.2)$ & $40(54.1)$ & \\
\hline$\pi$ & $40(23.2)$ & $20(27.0)$ & \\
\hline Neuropsychological Tests (SD) & & & \\
\hline Rey Visual Memory Immediate Recall & $21.1(6.8)$ & $19.1(6.3)$ & 0.02 \\
\hline Rey Visual Memory Delayed Recall & $21.2(6.5)$ & $19.3(7.03)$ & 0.043 \\
\hline CVLT-\| ${ }^{e}$ Trials 1-5 Score (Learning) & $53.9(11.1)$ & $48.7(11.4)$ & 0.0009 \\
\hline CVLT-II Short Delay Recall Score & $11.4(3.4)$ & $10.7(3.7)$ & 0.18 \\
\hline CVLT-II Long Delay Recall Score & $12.1(3.5)$ & $10.5(3.7)$ & 0.0008 \\
\hline WCST- ${ }^{\mathrm{f}}$ Total Errors & $23.2(21.7)$ & $24.5(22.3)$ & 0.67 \\
\hline WCST- Perseverative Responses (Percentile) & $50(28.9)$ & $49.9(31)$ & 0.95 \\
\hline WCST-Categories & $5.2(1.7)$ & $5.1(1.8)$ & 0.53 \\
\hline TMTg A Time (seconds) & $29.6(10.7)$ & $31.2(11.6)$ & 0.28 \\
\hline TMT B Time (seconds) & $71.5(29.7)$ & $80.8(34.9)$ & 0.03 \\
\hline PGNG ${ }^{\mathrm{h}}$ Response Time (Level 1) & $463.5(50.8)$ & $467.9(56.5)$ & 0.5 \\
\hline PGNG Target Accuracy (Level 1) & $0.9(0.1)$ & $0.9(0.1)$ & 0.10 \\
\hline
\end{tabular}

${ }^{a} S G A$ atypical antipsychotic, ${ }^{b} H A M D$ the Hamilton rating scale for depression; ${ }^{C} Y M R S$ Young mania rating scale, ${ }^{d} N O S$ not otherwise specified, ${ }^{e} C V L T-I / C a l i f o r n i a$ verbal learning test-II, ${ }^{f}$ WCST Wisconsin card sorting test, ${ }^{9} T M T$ trail making test, ${ }^{\mathrm{h}} P G N G$ parametric go-no-go test

also exhibited lower cognitive control scores as measured by the PGNG-Accuracy score $\left(p=0.004 ; \beta=0.083 ; r^{2}=\right.$ $0.23)$ compared to those with non-SGA, however, these results were not significant when considering CPZ- equivalents $\left(p=0.1 ; \beta=-0.0001 ; r^{2}=0.12\right)$ Interestingly, there were no significant cognitive deficiencies between treatment groups when stratified for the heterozygous (GT) or the homozygous minor allele (TT) genotypes. 
Table 2 Effects of SGA on mean cognitive stores stratified by COMT rs5993883 genotype

\begin{tabular}{|c|c|c|c|c|c|c|c|c|c|c|c|c|c|c|c|}
\hline \multirow[t]{2}{*}{ COMT rs5993883 } & \multicolumn{5}{|l|}{$\mathrm{GG}(n=58)$} & \multicolumn{5}{|l|}{$\mathrm{GT}(n=128)$} & \multicolumn{5}{|l|}{$\Pi(n=52)$} \\
\hline & No-SGA (STD) & SGA (STD) & beta & $p$ value & $r^{2}$ & No-SGA (STD) & SGA (STD) & beta & $p$ value & $r^{2}$ & No-SGA (STD) & SGA (STD) & beta & $p$ value & $r^{2}$ \\
\hline Rey Visual Memory Immediate recall & $20.9(6.9)$ & $17.4(7.2)$ & -4.13 & 0.09 & 0.15 & $20.7(6.7)$ & $19.2(6.4)$ & -1.8 & 0.88 & 0.22 & $22.2(6.9)$ & $20.0(5.5)$ & -2.2 & 0.27 & 0.16 \\
\hline Rey Visual Memory Delayed recall & $20.6(6.9)$ & $17.4(7.4)$ & -3.96 & 0.11 & 0.14 & $21.0(6.2)$ & $19.3(7.4)$ & -0.14 & 0.91 & 0.19 & $22.3(6.8)$ & $20.6(6.1)$ & -2.25 & 0.25 & 0.23 \\
\hline CVLT- $\|^{\mathrm{a}}$ learning score & $56.6(10.1)$ & $45.1(11.7)$ & 10.88 & 0.0006 & 0.51 & $52.0(12.2)$ & $49.3(10.9)$ & -1.77 & 0.46 & 0.17 & $55.2(8.9)$ & $50.1(12.0)$ & -2.77 & 0.32 & 0.36 \\
\hline CVLT-II short term delayed free recall & $11.6(3.2)$ & $9.8(4.5)$ & -1.6 & 0.18 & 0.15 & $11.0(3.4)$ & $10.9(3.5)$ & -0.12 & 0.85 & 0.15 & $12.0(3.4)$ & $11.1(3.8)$ & -0.68 & 0.54 & 0.12 \\
\hline CVLT-II long-term delayed free recall & $12.9(3.1)$ & $9.4(3.2)$ & -3.43 & 0.0026 & 0.28 & $11.4(3.7)$ & $10.7(3.1)$ & -0.22 & 0.75 & 0.18 & $12.7(3.1)$ & $11.0(3.1)$ & -0.92 & 0.29 & 0.19 \\
\hline WCST ${ }^{\mathrm{b}}$ total errors & $24.4(23.5)$ & $27.5(19.1)$ & 9.3 & 0.21 & 0.21 & $25.1(22.9)$ & $23.7(22.9)$ & -1.17 & 0.7 & 0.19 & $17.7(15.9)$ & $24.1(24.2)$ & 6.7 & 0.23 & 0.3 \\
\hline WCST perseverative responses & $14.3(15.4)$ & $15.4(14.6)$ & 4.98 & 0.33 & 0.16 & $15.4(16.3)$ & $14.1(16.4)$ & -1.61 & 0.62 & 0.18 & $9.5(9.2)$ & $14.5(17.3)$ & 5.27 & 0.17 & 0.25 \\
\hline WCST number of categories & $5.2(1.7)$ & $5.2(1.3)$ & -0.4 & 0.47 & 0.12 & $5.1(1.7)$ & $5.1(1.9)$ & 0.07 & 0.83 & 0.16 & $5.5(1.4)$ & $5.0(1.9)$ & -0.52 & 26 & 0.28 \\
\hline TMT Part A Time (sec) & $30.5(13.3)$ & $34.2(10.9)$ & 3.73 & 0.39 & 0.15 & $29.6(9.9)$ & $30.5(11.9)$ & 0.042 & 0.98 & 0.15 & $28.4(9.3)$ & $30.5(11.5)$ & 1.3 & 0.62 & 0.4 \\
\hline TMT Part B Time (sec) & $75.9(36.5)$ & $82.1(30.6)$ & 2.44 & 0.83 & 0.16 & $72.5(27.4)$ & $80.6(36.4)$ & 3.5 & 0.55 & 0.25 & $65.2(25.6)$ & $80.5(36.5)$ & 10.6 & 0.2 & 0.35 \\
\hline PGNG ${ }^{c}$ response time (msec) & $468.2(47.2)$ & $492.2(61.6)$ & 18.6 & 0.33 & 0.19 & $467.5(53.4)$ & $463.8(59.5)$ & -1.79 & 0.55 & 0.2 & $451.2(46.8)$ & $459.6(43.5)$ & 11.3 & 0.38 & 0.22 \\
\hline PGNG Target accuracy (\%) & $0.96(0.05)$ & $0.88(0.11)$ & 0.083 & 0.004 & 0.23 & $0.95(0.07)$ & $0.95(0.06)$ & 0.002 & 0.86 & 0.17 & $0.98(0.05)$ & $0.96(0.07)$ & -0.02 & 0.23 & 0.12 \\
\hline
\end{tabular}

This model was adjusted for age, education, gender, diagnosis, prior hospitalizations, benzodiazepines and antidepressant use

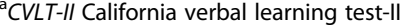

${ }^{\mathrm{b}}$ WCST Wisconsin card sorting test 


\section{Interaction of COMT rs5993883 genotype GG with SGAs on verbal cognition and impulsivity}

Due the observation that these SGA-associated cognitive deficits were only observed in the GG strata, we combined the GT and TT groups and used their scores as a comparator to the GG genotype to measure an interaction between genotype and verbal learning, verbal memory and cognitive control in SGA and non-SGA treatment populations (linear regression 2; Table 3). Also included in this regression model was the contribution of the genotype itself without the SGA-interaction, which combined the GT and TT populations and compared it to the GG genotype. Interestingly, the COMT genotype itself was a significant parameter in this model. We also observed a significant interaction between SGA treatment and COMT genotype on verbal learning ( $p=$ $\left.0.028 ; \beta=7.95 ; r^{2}=0.25\right)$ and verbal long-term delayed memory $\left(p=0.026 \beta=2.38 ; r^{2}=0.21\right)$. We also found a significant interaction between genotype and SGAtreatment when examining deficits in cognitive control. $\left(p=0.0005 ; \beta=0.083 ; r^{2}=0.15\right)$.

\section{Discussion}

In this work, we found an association between the GG genotype of COMT rs5993883 and SGA-treatment with these individuals with $\mathrm{BD}$ showing poorer cognitive performance than those with the GT or TT genotypes. Specifically, we observed significantly lower scores in areas of verbal cognition and cognitive control in this treatment population, indicating that individuals with $\mathrm{BD}$ who receive SGA treatment and have the GG genotype are at risk for greater difficulties in learning and remembering verbal or auditory information and they are less accurate when required to engage and disengage their attention to stimuli. Overall, they may be less efficient with learning, memory, and attentional capacity. Although the results of the PGNG Target Accuracy test was not significant when considering CPZ-equivalents, this may be due to non-dose dependent pharmacologic effects. This cohort also exhibited a significant interaction between the SGA-class of medication and COMT genotype in the same cognitive domains.
Neuropsychological studies of patients with brain injuries and neuroimaging work has indicated that dopamine action in the prefrontal cortex, dorsal striatum and hippocampus is critical for high level cognitive functioning [32-34]. O-methylation by COMT is one of the major degradative pathways for catecholamine neurotransmitters such as dopamine [15]. Consistent with its role in catecholamine metabolism in the prefrontal cortex, variation in this gene has been linked with decreased cognitive function in BD, schizophrenia and in healthy controls $[14,16,35]$. The most widely studied COMT variant allele is the COMT Val108/158Met polymorphism rs4680. This variant affects the stability and enzymatic activity of catechol-O-methyltransferase, which alters the enzyme's ability to methylate catecholamines in the prefrontal cortex [36-38]. In previous work, Val allele load has been associated with detrimental effects in cognition for schizophrenia subjects and has also been linked to a further decrease in cognition in $\mathrm{BD}$ patients treated with SGAs [9].

The polymorphism COMT rs5993883 is located in intron 1 of the COMT gene and is not strongly linked to the rs4680 polymorphism (Distance $=13633$ base pairs; $r^{2}=.327 ; \mathrm{d}^{\prime}=0.654 ;$ www.broadinstitute.org $\left./ \mathrm{mpg} / \mathrm{snap} /\right)$. In previous work, this mutation has been weakly associated with creativity, cocaine induced paranoia and modulation of certain personality traits including suicidal behavior $[15,39,40]$. Additionally, the rs5993883 G allele has been associated with cognitive manic symptoms in BD patients [41]. Intron variants are not in the protein-coding region of a gene but can generally affect function by altering processes such as transcription or alternative splicing, in which several splice variants have been noted for COMT [42-44]. Although no structural or transcriptional changes in function have been defined for COMT rs5993883, it's possible that this variant could affect these types of processes.

Impairments in cognition are noted as being robustly evident in the schizophrenia literature but have also been noted in $\mathrm{BD}$ patients, although to a lesser degree. When compared to healthy controls, euthymic BD patients show deficiency in executive functioning, verbal memory, psychomotor speed and sustained attention

Table 3 Interaction between SGA and COMT polymorphism rs5993883 on cognition in bipolar patients (using GG genotype as a reference)

\begin{tabular}{|c|c|c|c|c|c|c|}
\hline \multirow[t]{2}{*}{ Cognitive parameter } & \multicolumn{2}{|c|}{ Verbal attention ${ }^{\mathrm{a}}\left(r^{2}=0.25\right)$} & \multicolumn{2}{|c|}{ Verbal delayed recall ${ }^{\mathrm{a}}\left(r^{2}=0.21\right)$} & \multicolumn{2}{|c|}{ Cognitive control $^{\mathrm{b}}\left(r^{2}=0.15\right)$} \\
\hline & beta & $p$ value & beta & $p$ value & beta & $p$ value \\
\hline$\overline{S G A}$ & -10.03 & 0.0019 & -3.03 & 0.0022 & -0.08 & $<0.0001$ \\
\hline COMT genotype & -4.65 & 0.013 & -1.43 & 0.013 & -0.007 & 0.54 \\
\hline Main Interaction & 7.95 & 0.028 & 2.38 & 0.026 & 0.083 & 0.0005 \\
\hline
\end{tabular}

This model was adjusted for age, education, gender, diagnosis, prior hospitalizations, benzodiazepines and antidepressant use

${ }^{a}$ Age, education and gender were also significant parameters in this model

${ }^{\mathrm{b}} \mathrm{Age}$ was also a significant parameter in this model 
[45]. It has also been observed that in first degree relatives, the cognitive domains of executive functioning and verbal memory are significantly different from healthy controls, which suggests these domains are bipolar endophenotypes reflecting a genetic link to BD [46]. Impaired inhibitory behavioral control in manic and euthymic BD subjects is a specific cognitive impairment that has also been described as distinct from the universal neuropsychological deficiency linked to other psychotic disorders [47, 48]. The overall cause of neurocognitive deficits in BD patients is likely multifactorial including genetic, medication and symptom considerations. Although deficiencies in verbal memory have been described in the BD population, we have observed further decrements in this domain due to an interaction between SGA-treatment and the GG genotype of the COMT rs5993883 variant. We also described a relationship between COMT rs5993883 and SGA-treatment on deficiencies in cognitive control as measured by a continuous performance test (PGNG).

Second generation antipsychotics have a role in the management of not only BD-associated mania but are also effective in BP-associated depression. Although the mechanistic basis for the efficacy of SGAs in mood disorders is not completely understood, the ability to block $\mathrm{D} 2$ and serotonin $5 \mathrm{HT}_{2 \mathrm{~A}}$ receptors are likely to contribute. Dopamine dysregulation is thought have a role in the psychopathology of BD [49]. However, in contrast to the cognitive improvement observed in SGA-treated schizophrenia patients, SGAs use within the BD population has been associated with lower cognitive functioning. As a further complication for cognition in this group, our work and others have shown that treatment with SGAs may confer further decrements in cognition if the subject caries COMT variants [9]. In this report, we observe that a well-characterized large group of $\mathrm{BD}$ subjects show significantly lower cognitive performance in specific domains of verbal cognition and cognitive control that are associated with an SGA-treatment interaction with a GG genotype of COMT rs5993883.

\section{Study limitations}

As this study was cross-sectional in design, we miss looking longitudinally at cognitive measures in APP-treated subjects over time. In the future, as we accumulate more data in the Prechter longitudinal cohort, a longitudinal analytic approach will be informative. Additionally, we know that members of the SGA-class are not identical in either the mechanism of action or side effects. In this study, we did not distinguish between specific SGAmedications but this may be warranted in future work.

Greater severity of illness is associated with SGA treatment in the BD population, which can also result in reduced cognitive functioning. In an attempt to address this disparity, we adjusted our model for prior hospitalizations, as an indicator of disease severity, which showed a statistically significant increase in the SGA-treated population. However, it may also be important to consider other factors such as medication switching or chlorpromazine equivalents for SGA use to assess severity of illness. And finally, we also had a significantly under representation of the BD-II and schizoaffective BD type diagnoses when compared to subjects with a BD-I diagnosis. There may be differences in the effect of COMT variant alleles and interactions with SGA-treatment in the less-represented diagnosis in our subject cohort. As we accrue more subjects, this analysis may be possible using the Prechter cohort.

\section{Conclusions}

This investigation contributes to work illustrating links between cognition, SGA-treatment and COMT in BD subjects. Our analysis highlights significant associations between decreased verbal-cognition and cognitive control in SGA-treated subjects carrying the COMT rs5993883 GG-genotype. Prospective studies are needed to assess the clinical importance of these findings.

\section{Ethics approval and consent to participate}

The Prechter Lonigtudinal Study of Bipolar Disorder has been approved by the University of Michigan Institutional Review Board (HUM00000606).

\section{Availability of data and materials}

The the Heinz C. Prechter Bipolar Research study is an ongoing study. Materials are not public at this time.

\section{Additional file}

Additional file 1: Table S1. Atypical Antipsychotics, benzodiazepines and antidepressants used in this study. (XLS $9 \mathrm{~kb}$ )

\section{Abbreviations}

BD: bipolar disorder; COMT: catechol-o-methyltransferase; CVLT-II: The California verbal learning test-II; DIGS: diagnostic interview for genetic studies; HDRS: Hamilton depression rating-17 item; NOS: not otherwise specified; PGNG: parametric go/no-go task; Rey: The Rey-Osterrieth complex figure test; SGAs: second generation antipsychotics; TMT: trail making test parts $A$ and $B ;$ WCST: Wisconsin card sorting test; YMRS: Young mania rating scale.

\section{Competing interests}

The authors declare that they have no competing interests.

\section{Authors' contributions}

SF is the lead author and has made substantial contributions to conception, design, data analysis and drafting of the manuscript. KR is the neuropsychology consult and made significat contributions to the study design (applicable neuropsych tests) and data acquisition of neuropsych scores and contributions to writing the manuscript. ZL is our statistics consult and had a critical role in data acquisition, analysis, interpretation and manuscript revision. MM is the director of the Prechter Bipolar Research Program and contributed greatly to data acquisition, interpretation and for the drafting/revision of the manuscript. VE is the senior PI for the project. She made substantial contributions to the 
study design, drafting of the manuscript and manuscript revision. All authors read and approved the final manuscript.

\section{Acknowledgements}

\section{Funding}

This work is supported by the Heinz C. Prechter Bipolar Research Fund and the Richard Tam Foundation at the University of Michigan Depression Center. This work is also supported by grants from The National Institute for Mental Health under Award Number R01MH082784.

\section{Author details}

${ }^{1}$ Clinical Pharmacy Department, College of Pharmacy, University of Michigan, 428 Church St, Ann Arbor, Ml 48109-106, USA. ²Department of Psychiatry, School of Medicine, University of Michigan, 4250 Plymouth Rd, Ann Arbor, M 48109, USA. ${ }^{3}$ Center for Clinical Management Research (CCMR) Veterans Affairs, Ann Arbor, USA.

Received: 23 September 2015 Accepted: 24 March 2016 Published online: 02 April 2016

\section{References}

1. Seeman P. Second generation antipsychotics: mechanism of action. Can J Psychiatry. 2002;47:27-38

2. Clark L, Kempton MJ, Scarnà A, Grasby PM, Goodwin GM. Sustained attention-deficit confirmed in euthymic bipolar disorder but not in firstdegree relatives of bipolar patients or euthymic unipolar depression. Biol Psychiatry. 2005;57:183-7

3. Martínez-Arán A, Vieta E, Reinares M, Colom F, Torrent C, Sánchez-Moreno J, Benabarre A, Goikolea JM, Comes M, Salamero M. Cognitive function across manic or hypomanic, depressed, and euthymic states in bipolar disorder. Am J Psychiatry. 2004;161:262-70.

4. Ryan KA, Vederman AC, McFadden EM, Weldon AL, Kamali M, Langenecker SA, McInnis MG. Differential executive functioning performance by phase of bipolar disorder. Bipolar Disord. 2012;14:527-36.

5. Goldberg TE, Goldman RS, Burdick KE, Malhotra AK, Lencz T, Patel RC, Woerner MG, Schooler NR, Kane JM, Robinson DG. Cognitive improvement after treatment with second-generation antipsychotic medications in firstepisode schizophrenia: is it a practice effect? Arch Gen Psychiatry. 2007;64: $1115-22$.

6. Keefe RSE, Bilder RM, Davis SM, Harvey PD, Palmer BW, Gold JM, Meltzer HY, Green MF, Capuano G, Stroup TS, McEvoy JP, Swartz MS, Rosenheck RA, Perkins DO, Davis CE, Hsiao JK, Lieberman JA. Neurocognitive effects of antipsychotic medications in patients with chronic schizophrenia in the CATIE Trial. Arch Gen Psychiatry. 2007:64:633-47.

7. Heinrichs RW. Cognitive improvement in response to antipsychotic drugs: neurocognitive effects of antipsychotic medications in patients with chronic schizophrenia in the CATIE Trial. Arch Gen Psychiatry. 2007;64:631-2.

8. Wang J, Hu M, Guo X, Wu R, Li L, Zhao J. Cognitive effects of second generation antipsychotic drugs in first-episode drug-naïve schizophrenic patients. Neural Regen Res. 2013;8:277-86.

9. Arts B, Simons CJP, Drukker M, van Os J. Antipsychotic medications and cognitive functioning in bipolar disorder: moderating effects of COMT Val108/158 Met genotype. BMC Psychiatry. 2013;13:63.

10. Dias W, Balanzá-Martinez V, Soeiro-de-Souza MG, Moreno RA, Figueira ML, Machado-Vieira R, Vieta E. Pharmacological approaches in bipolar disorders and the impact on cognition: a critical overview. Acta Psychiatr Scand. 2012 126:315-31.

11. Cousins DA, Butts K, Young AH. The role of dopamine in bipolar disorder. Bipolar Disord. 2009;11:787-806.

12. Berk M, Dodd S, Kauer-Sant'anna M, Malhi GS, Bourin M, Kapczinski F, et al. Dopamine dysregulation syndrome: implications for a dopamine hypothesis of bipolar disorder. Acta Psychiatr Scand Suppl. 2007;41-9.

13. McIntosh AM, Baig BJ, Hall J, Job D, Whalley HC, Lymer GK, Moorhead TW Owens DG, Miller P, Porteous D, Lawrie SM, Johnstone EC. Relationship of catechol-O-methyltransferase variants to brain structure and function in a population at high risk of psychosis. Biol Psychiatry. 2007:61(10):1127-34.

14. Burdick KE, Funke B, Goldberg JF, Bates JA, Jaeger J, Kucherlapati R, Malhotra AK. COMT genotype increases risk for bipolar I disorder and influences neurocognitive performance. Bipolar Disord. 2007;9:370-6.
15. Takizawa R, Tochigi M, Kawakubo Y, Marumo K, Sasaki T, Fukuda M, Kasai K. Association between catechol-O-methyltrasferase Val108/158Met genotype and prefrontal hemodynamic response in schizophrenia. PLoS One. 2009; 4(5):e5495.

16. Barnett $J H$, Scoriels L, Munafò MR. Meta-analysis of the cognitive effects of the catechol-O-methyltransferase gene Val158/108Met polymorphism. Biol Psychiatry. 2008;64:137-44

17. Bosia M, Zanoletti A, Spangaro M, Buonocore M, Bechi M, Cocchi F, Pirovano A, Lorenzi C, Bramanti P, Smeraldi E, Cavallaro R. Factors affecting cognitive remediation response in schizophrenia: the role of COMT gene and antipsychotic treatment. Psychiatry Res. 2014;217:9-14.

18. Apud JA, Weinberger DR. Treatment of cognitive deficits associated with schizophrenia: potential role of catechol-O-methyltransferase inhibitors. CNS Drugs. 2007;21:535-57

19. Weickert TW, Goldberg TE, Mishara A, Apud JA, Kolachana BS, Egan MF, Weinberger DR. Catechol-O-methyltransferase val108/158met genotype predicts working memory response to antipsychotic medications. Biol Psychiatry. 2004;56:677-82.

20. Chan RCK, Chen RYL, Chen EYH, Hui TCK, Cheung EFC, Cheung HK, Sham P, $\mathrm{Li}$ T, Collier D. The differential clinical and neurocognitive profiles of COMT SNP rs165599 genotypes in schizophrenia. J Int Neuropsychol Soc. 2005;11: 202-4.

21. Jen A, Saunders EF, Ornstein RM, Kamali M, McInnis MG. Impulsivity, anxiety, and alcohol misuse in bipolar disorder comorbid with eating disorders. Int J bipolar Disord. 2013;1:13.

22. Nurnberger JI, Blehar MC, Kaufmann CA, York-Cooler C, Simpson SG, Harkavy-Friedman J, Severe JB, Malaspina D, Reich T. Diagnostic interview for genetic studies. Rationale, unique features, and training. NIMH Genetics Initiative. Arch Gen Psychiatry. 1994;51:849-59. discussion 863-4.

23. Hamilton M. Development of a rating scale for primary depressive illness. Br J Soc Clin Psychol. 1967;6:278-96.

24. Young RC, Biggs JT, Ziegler VE, Meyer DA. A rating scale for mania: reliability, validity and sensitivity. Br J Psychiatry. 1978;133:429-35.

25. Langenecker SA, Saunders EFH, Kade AM, Ransom MT, McInnis MG. Intermediate: cognitive phenotypes in bipolar disorder. J Affect Disord. 2010;122:285-93.

26. Delis D, Kramer J, Kaplan E, BA O. California verbal learning test-II. 2nd ed. San Antonio: The Psychological Corporation; 2000.

27. Schoenberg MR, Dawson KA, Duff K, Patton D, Scott JG, Adams RL. Test performance and classification statistics for the Rey auditory verbal learning test in selected clinical samples. Arch Clin Neuropsychol. 2006;21:693-703.

28. Buhlmann U, Deckersbach T, Engelhard I, Cook LM, Rauch SL, Kathmann N, Wilhelm S, Savage CR. Cognitive retraining for organizational impairment in obsessive-compulsive disorder. Psychiatry Res. 2006;144:109-16.

29. Heaton R. A manual for the Wisconsin card sorting test. Odessa: Psychological Assessment Resources; 1981.

30. War. Army individual test battery: manual of directions and scoring Washington, DC: War Department Adjutant General's Office; 1944.

31. Langenecker SA, Zubieta JK, Young EA, Akil H, Nielson KA. A task to manipulate attentional load, set-shifting, and inhibitory control: convergent validity and test-retest reliability of the parametric Go/No-Go test. J Clin Exp Neuropsychol. 2007;29:842-53.

32. Clark L, Cools R, Robbins TW. The neuropsychology of ventral prefrontal cortex: decision-making and reversal learning. Brain Cogn. 2004;55:41-53.

33. Benton AL. Neuropsychological assessment. Annu Rev Psychol. 1994:45:1-23.

34. Cools R. Dopaminergic control of the striatum for high-level cognition. Curr Opin Neurobiol. 2011:21:402-7.

35. Malhotra AK, Kestler LJ, Mazzanti C, Bates JA, Goldberg T, Goldman D. A functional polymorphism in the COMT gene and performance on a test of prefrontal cognition. Am J Psychiatry. 2002;159(4):652-4.

36. Egan MF, Goldberg TE, Kolachana BS, Callicott JH, Mazzanti CM, Straub RE, Goldman D, Weinberger DR. Effect of COMT Val108/158 Met genotype on frontal lobe function and risk for schizophrenia. Proc Natl Acad Sci U S A. 2001;98:6917-22.

37. Ittiwut R, Listman JB, Ittiwut C, Cubells JF, Weiss RD, Brady K, Oslin D, Farrer LA, Kranzler HR, Gelernter J. Association between polymorphisms in catechol-Omethyltransferase (COMT) and cocaine-induced paranoia in EuropeanAmerican and African-American populations. Am J Med Genet B Neuropsychiatr Genet. 2011;156B:651-60.

38. Du L, Merali Z, Poulter MO, Palkovits M, Faludi G, Anisman H Catechol-Omethyltransferase Val158Met polymorphism and altered COMT gene expression 
in the prefrontal cortex of suicide brains. Prog Neuropsychopharmacol Biol Psychiatry. 2014:50:178-83.

39. Zhang S, Zhang M, Zhang J. Association of COMT and COMT-DRD2 interaction with creative potential. Front Hum Neurosci. 2014;8:216.

40. Calati R, Porcelli S, Giegling I, Hartmann AM, Möller HJ, De Ronchi D, Serretti A, Rujescu D. Catechol-o-methyltransferase gene modulation on suicidal behavior and personality traits: review, meta-analysis and association study. J Psychiatr Res. 2011;45:309-21.

41. Hukic DS, Frisén L, Backlund L, Lavebratt C, Landén M, Träskman-Bendz L,Edman G, Schalling M, Ösby U. Cognitive manic symptoms in bipolar disorder associated with polymorphisms in the DAOA and COMT genes. PLoS One. 2013;8(7), e67450.

42. Tunbridge $E M$, Weinberger DR, Harrison PJ. A novel protein isoform of catechol O-methyltransferase (COMT): brain expression analysis in schizophrenia and bipolar disorder and effect of Val158Met genotype. Mol Psychiatry. 2005;11:116-7.

43. Huh MM, Friedhoff AJ. Multiple molecular forms of catechol-Omethyltransferase. Evidence for two distinct forms, and their purification and physical characterization. J Biol Chem. 1979;254:299-308.

44. Nackley AG, Shabalina SA, Tchivileva IE, Satterfield K, Korchynskyi O, Makarov SS, Maixner W, Diatchenko L. Human catechol-O-methyltransferase haplotypes modulate protein expression by altering mRNA secondary structure. Science. 2006;314:1930-3.

45. Bora E, Yucel M, Pantelis C. Cognitive endophenotypes of bipolar disorder: A meta-analysis of neuropsychological deficits in euthymic patients and their first-degree relatives. J Affect Disord. 2009:113:1-20.

46. Stone WS, Giuliano AJ, Tsuang MT, Braff DL, Cadenhead KS, Calkins ME, Dobie DJ, Faraone S V, Freedman R, Green MF, Greenwood TA, Gur RE, Gur RC, Light GA, Mintz J, Nuechterlein KH, Olincy A, Radant AD, Roe AH, Schork NJ, Siever LJ, Silverman JM, Swerdlow NR, Thomas AR, Tsuang DW, Turetsky Bl, Seidman LJ. Group and site differences on the California verbal learning test in persons with schizophrenia and their first-degree relatives: findings from the consortium on the genetics of schizophrenia (COGS). Schizophr Res. 2011; 128:102-10.

47. Henry BL, Minassian A, Patt VM, Hua J, Young JW, Geyer MA, Perry W. Inhibitory deficits in euthymic bipolar disorder patients assessed in the human behavioral pattern monitor. J Affect Disord. 2013:150:948-54

48. Ethridge LE, Soilleux M, Nakonezny PA, Reilly JL, Hill SK, Keefe RSE, Gershon ES, Pearlson GD, Tamminga CA, Keshavan MS, Sweeney JA. Behavioral response inhibition in psychotic disorders: diagnostic specificity, familiality and relation to generalized cognitive deficit. Schizophr Res. 2014;159:491-8.

49. Strejlevich SA, Teitelbaum J, Martino DJ, Quiroz D, Kapczinski F. Dopamine sudden depletion as a model for mixed depression. Med Hypotheses. 2012; 78:107-12.

\section{Submit your next manuscript to BioMed Central and we will help you at every step:}

- We accept pre-submission inquiries

- Our selector tool helps you to find the most relevant journal

- We provide round the clock customer support

- Convenient online submission

- Thorough peer review

- Inclusion in PubMed and all major indexing services

- Maximum visibility for your research

Submit your manuscript at www.biomedcentral.com/submit

C Biomed Central 